
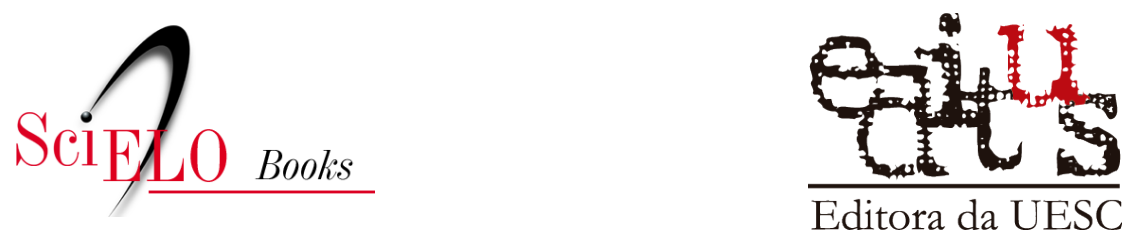

\title{
7 A dignificação da identidade quilombola a partir das memórias
}

Raíssa Félix

\section{SciELO Books / SciELO Livros / SciELO Libros}

FÉLIX, R. A dignificação da identidade quilombola a partir das memórias. In: Volta miúda: quilombo, memória e emancipação [online]. Ilhéus, BA: Editus, 2020, pp. 165-178. Transfluência series. ISBN: 978-65-86213-14-0. https://doi.org/10.7476/9786586213317.0008.

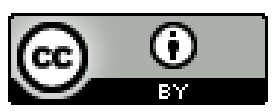

All the contents of this work, except where otherwise noted, is licensed under a Creative Commons Attribution 4.0 International license.

Todo o conteúdo deste trabalho, exceto quando houver ressalva, é publicado sob a licença Creative Commons Atribição 4.0.

Todo el contenido de esta obra, excepto donde se indique lo contrario, está bajo licencia de la licencia Creative Commons Reconocimento 4.0. 


\section{A dignificação da identidade quilombola a partir das memórias}

A promoção da interação com vistas a contribuir com a justiça social e cognitiva perpassa pela compreensão do próprio conceito/categoria designada pelo termo "quilombo". Ao levantar os significados que lhe são atribuídos, José Maurício Arruti (2006, p. 121) assevera que a "categoria 'remanescente de quilombos' é um exemplo privilegiado de como o poder simbólico de nomeação depositado no Estado pode, ao menos em parte, criar as próprias coisas nomeadas". O antropólogo elucida que o termo "quilombo" sofreu um processo de ressemantização ao longo dos séculos, e se refere ao termo "remanescente quilombola" como uma "alquimia semântica" (ARRUTI, 2006, p. 70), cercado de certo tom mitológico e metafórico, carregado de simbolismo cultural e histórico. Outrora entendido como reunião de escravos fugidos, o termo quilombo passou a ser visto como instituição de resistência cultural, visto que reúne, simbolicamente, os modos de ser e viver dos povos africanos escravizados e seus descendentes (ARRUTI, 2006, p. 72); resistência política, ao evidenciar e situar a disputa de poder entre classes / 
segmentos sociais que se opõem, com vistas a alcançar, para além da preservação da sua cultura, a luta contra a escravidão como sistema econômico e social (ARRUTI, 2006, p. 7375); e, também aborda o uso do quilombo enquanto "ícone da 'resistência negra'". A agregação do termo "remanescente" passou a evocar a existência em substância - e não apenas reminiscências memoriais - da presença negra africana e descendente como conformadora da sociedade.

Ao rememorar Abdias do Nascimento, Arruti contempla uma novação semântica do termo, pois, para aquele autor, "Quilombo não significa escravo fugido. Quilombo quer dizer reunião fraterna e livre, solidariedade, convivência, comunhão existencial" (NASCIMENTO, 1980, p. 263 apud ARRUTI, 2006, p. 76), de maneira que "comunidade quilombola" se realiza não apenas em coletividades que remanescem de quilombos, mas em todas que se apresentam como ícones de resistência dos modos de vida afrocentrados, como Volta Miúda. A ressemantização culmina, portanto, na noção de uma coletividade de origem sócio-histórico-cultural comum, oriunda de negros escravizados ou não, que agrega as noções de resistência política e cultural - que os coloca como coletivo hábil à luta pelo reconhecimento e percepção de direitos e cidadania.

O termo quilombo é uma categoria jurídica usada pelo Estado brasileiro a partir da Promulgação da Constituição Federal de 1988, visando assegurar a propriedade definitiva às comunidades negras rurais dotadas de uma trajetória histórica própria e relações territoriais específicas, bem como ancestralidade negra relacionada com o período escravocrata. Nesse sentido, há outras terminologias para o termo quilombo, como Terras de Preto, Terras de Santo, Mocambo, Terra de Pobre, entre outros. (SANTOS; ROCHA, 2017, p. 2). 
A supressão do termo "remanescente", apesar de simples, reverbera na ampliação do conceito já apresentado por Abdias Nascimento, que abdica do critério estritamente histórico - que renuncia a ideia de uma continuidade de um quilombo no período escravista até os dias atuais para abarcar a trajetória das comunidades que desempenham o papel de resistência cultural. De acordo com a professora da Faculdade de Educação da Universidade de Brasília (FE/ UnB) e pesquisadora da realidade quilombola, Glória Moura, "a realidade quilombola e sua forte influência na história de resistência do negro no Brasil" tem importância "para toda a História do país e a reafirmação da identidade étnica dos brasileiros" (FUNDAÇÃO CULTURAL PALMARES, 2012). E neste âmbito reforça: manter-se sensível à escuta das memórias e saberes de anciãs/os quilombolas é, ao mesmo tempo, contribuir para a efetivação da humanidade tanto de ouvintes quanto de narradores, e possibilitar-lhes a efetivação do direito à memória. Quilombo se concebe enquanto resistência num processo político em que há concorrência de forças e o desenvolvimento de estratégias para preservação da sua história, cultura e religiosidade, acessíveis, especialmente, por meio da história oral.

Brasília Firmina manifesta suas memórias como combatentes à racialização e hierarquização social. Além de tecer duras críticas à monocultura do eucalipto, ao relacioná-la ao estado socioeconômico reservado à comunidade, outrora rica em sua diversidade e fertilidade, expressa sua visão de mundo comunalista: "O eucalipto tomou o mundo todo, por isso que não tem nada pra povo comer mais [...] Porque só eles ganha e os outro não ganha? Vive de quê?", questiona a quilombola ao ressaltar que "Deus deixou o mundo 
muito grande, [se hoje falta alimento e água] é porque um só quer abraçar o mundo todo" (Brasília Firmina, 3 de março de 2019). O conhecimento da Volta Miúda de um tempo passado instala em Brasília Firmina a consciência de que não há determinismo em sua trajetória, e que as diferenças que percebe hoje advêm da ação direcionada de uma força político-econômica a quem responsabiliza pelos infortúnios vividos no presente, e ausentes no passado. O posicionamento de Dona Brasília denota não apenas racionalidade, mas uma inteligência crítica para a leitura da sua realidade.

O desfazimento dos modos de ser e viver afrocentrados fomentado, sobretudo, em função da imposição dos modos de ser e viver capitalista reverbera na vida de Berta d'Ajuda que, inserta num contexto quilombola e rural, é afetada pelo sistema colonial-capitalista que promove o apagamento das suas heranças socioculturais e mitiga a convivência, o caráter comunitário/humanista do grupo:

[...] O pessoal era muito unido, o pessoal da Volta Miúda. O pessoal perdia tempo pra ficá a semana toda ajudando você fazer quaqué coisa, trabalhá, ajudá né. Era muito unido, agora num é tanto mais assim. É mas não é. Igualmente, hoje em dia ninguém qué disprendê hora pra ajudar ninguém fazer nada. Hoje em dia não qué perdê, só qué sabê do dinheiro. Mais pra ir ver à toa, perdêassim, só ajudá sem dinheiro, ninguém qué perdê. Se tivé dinheiro você consegue, se não tivé, faz sozinho. (Berta d'Ajuda, 20 de fevereiro de 2019).

Berta fala sobre um modelo de sociedade que vulnera a existência de individualidades formadas sob valores que dissonam da mercantilização da vida. Sentimento e sentido - 
de vida, de mundo, de sociedade - são termos que dialogam. Berta sente falta da comunhão e proximidade que recheava, durante a sua infância e juventude, a sua convivência com as famílias quilombolas - cuja relação não se fundava no capital. Mas, ao reconhecer esta saudade, o faz com cautela, sem desfazer daqueles com quem ainda divide a vida de maneira interligada, conectada.

Manoel de Delfina é rezador do Santo Ofício, autoridade nas comunidades do Extremo Sul baiano, filho de Delfina Joaquina Josefa e neto de Joaquina Josefa, sempre destaca que a sua avó nasceu "no dia em que libertaram os escravo", foi nesta data, 13 de maio de 1888, que as bisavós e bisavôs de Seu Manoel, escravizados, foram libertos. Ele conhece de perto as ruínas da antiga senzala, e apresenta os arcos em pedra, um canal que desemboca no Rio Peruípe, a escadaria em pedra que leva a um terreiro e repete "isso aqui foi os escravo que fez" (Manoel de Delfina, 3 de março de 2019). A sua fala remete a um tom de apropriação sobre a realização arquitetônica dos seus antepassados - enquanto as mãos deslizam sobre a superfície plana e regular construída em pedra -, ao passo em que o tom elogioso é temperado pela inquietude da reflexão sobre 'como' a fizeram: lapidaram, carregaram, ergueram e assentaram pedras. Ao rememorar e tocar, literalmente, as reminiscências de um passado hostil e tão presente, Manoel de Delfina reflete sobre o seu vínculo com este território, de maneira salutar, afetiva, simbiótica, e afirma categoricamente: "Na cidade eu fico preso" (Manoel de Delfina, 3 de março de 2019) - ele desafia os limites da própria liberdade e questiona o conceito da famigerada (e moderna, no sentido histórico do conceito) liberdade. 
Ao contar sobre a forma como aprendeu o Santo Ofício, Manoel de Delfina ressalta "Eu sou nascido e criado aqui, nascido e criado em Volta Miúda. Nascido e criado dentro da Volta Miúda. E aprendi a cantá o Ofício, sem ninguém me ensiná, graças a Deus" (Manoel de Delfina, 8 de fevereiro de 2019) e abre, pelo menos, duas interpretações possíveis: a que aduz sobre o seu alijamento da participação ativa na sacralidade, pois, embora participasse do rito, Ihe foi negado o ensinamento por quem o conduzia, conforme relatou, e a capacidade de apreensão por meio da escuta e em decorrência da tomada da oralidade como modalidade precursora de conhecimento. Ao contar sobre a forma como se tornou rezador do Santo Ofício, Manoel de Delfina sempre enfatiza que aprendeu por observar, aprendeu a partir da experiência, ouvindo, sem que Ihe ensinassem. Exercia ele, por força das suas ancestralidades, o aprendizado a partir da oralidade e que se dá de maneira imbricada com as experiência do/ no mundo, pois

\footnotetext{
Uma vez que se liga ao comportamento cotidiano do homem e da comunidade, a "cultura" africana não é, portanto, algo abstrato que possa ser isolado da vida. Ela envolve uma visão particular do mundo, ou, melhor dizendo, uma presença particular no mundo - um mundo concebido como um Todo onde todas as coisas se religam e interagem. (HAMPATÉ BÂ, 2010, p. 169).
}

A tradição oral é lida como conhecimento total, passado pelos mais velhos aos mais novos, àqueles que tenham ouvidos sensíveis para aprender conhecimentos preservados há muitas gerações. Manoel de Delfina, ao reconhecer anciãs e anciãos como detentores de sabedoria e experiência 
acumulada durante a vida, reconheceu-os também como emissores, por excelência, do conhecimento total, manteve-se sensível e apreendeu o Santo Ofício.

É nesse mesmo ensejo que Berta d'Ajuda (20 de fevereiro de 2019) conta que aprendeu a fazer beiju, construir casa de taipa, plantar, fazendo, junto aos seus. Há, por parte da convivência estimulada nos modos de vida negra, uma transmissão de conhecimento que é orgânica, inerente à sua identidade, culturalmente intrínseca - que concebe e é originada por este modo particular de aprender e ensinar. A experiência como método de aprendizagem/experimentação está interligada à oralidade, haja vista que,

Ao fazer uma caminhada pela mata, encontrar um formigueiro dará ao velho mestre a oportunidade de ministrar conhecimentos diversos, de acordo com a natureza dos ouvintes. Ou falará sobre o próprio animal, sobre as leis que governam sua vida e a "classe de seres" a que pertence, ou dará uma lição de moral às crianças, mostrando-Ihes como a vida em comunidade depende da solidariedade e do esquecimento de si mesmo, ou ainda poderá falar sobre conhecimentos mais elevados, se sentir que seus ouvintes poderão compreendê-lo. Assim, qualquer incidente da vida, qualquer acontecimento trivial pode sempre dar ocasião a múltiplos desenvolvimentos, pode induzir à narração de um mito, de uma história ou de uma lenda. Qualquer fenômeno observado permite remontar às forças de onde se originou e evocar os mistérios da unidade da Vida, que é inteiramente animada pela Se, a Força sagrada primordial, ela mesma um aspecto do Deus Criador. (HAMPATÉ BÂ, 2010, p. 184). 
Ao se referir sobre o processo de construção das casas, derrubada da mata, plantio e colheita e beneficiamento da mandioca, Manoel de Delfina e Brasília Firmina relembram com cânticos o processo de ajuntamento e cooperação coletiva, que também demonstra a divisão sexual do trabalho:

Brasília Firmina: Pra ocê vê. Juntava pra fazer uma roça, tinha que juntar um bocado de homem. Tinha que juntar os home pra derrubar; as mulhé tá aí no rancho, que não tinha casa, num rancho pra fazer comida pros trabalhador, pros home. Aí os home cantava, cantava, com pouco a gente "olha vai cair derradeira madeira". Como é que a gente cantava? Derradeira madeira?

Manoel de Delfina: "Ô laranjeiro pá, ô laranjeiro pá, a madeira vai cair, ô laranjeiro pá."

B.F.: Vai cair derradeiro, e as mulhé que tá aí no rancho sabe. "Ó já tá terminando, vamo prontar a bandeira" - fazia duas bandeira de pano.

M.D.: Duas bandeira, tinha uma branca, outra azul.

B.F.: Marrada na ponta de uma vara assim ó, fica esgueiro assim. Quando os home é vem chegando, as mulher sai. Duas mulher, sai com essas duas bandeira cruzada, ainda cruzada e ia andando, quando chegava na porta entregava os home, vinha dois home também de lá recebia... a bandera. Como é que eles cantava?

M.D.: “Ó a bandera, bandera, ó bandera de iaiá, ó bandera, a bandera..."

B.F.: Agora a machadeira vem então com o machado: "dú, dú, dú".

M.D.: “Ó derrubada já acabou, ó bandeira, ó bandeira, 
oi bandeira. No poder do bastião, ó bandeira. 'Pelo siná, pelo siná', bandera do rei que é vem tomar."

B.F.: Quando cantava assim é a hora que as mulher ia entregar a bandeira. "'Pelo siná, pelo siná', bandeira do rei que é vem tomar". Quem vem tomar essa bandeira? "Bandera do rei que é vem tomar". Agora a gente entrega a eles a bandera e eles entra lá pra dentro com as bandera. Um monte de coisa de tempo. Naquele tempo... (24 de junho de 2018).

O pesquisador Gean Santana (2014, p, 141-142), ao rememorar o canto e o trabalho das negras e negros como celebração à vida, elucida que:

As bandeiras, assim como os tambores caburé e angoma, materializam a presença do divino no meio do povo negro. Não raro observarmos, nas casas de santo, a presença de um mastro que sustenta uma bandeira com bordados ou pinturas, representando o santo de devoção. Em Helvécia, constatamos uma forte devoção a São Sebastião [assim como em Volta Miúda], mártir católico, muito cultuado nos terreiros de culto de matriz africana, sincretizado no orixá Ogun.

O diálogo cantado é o enunciado duplo da integração construída pela cena: a narrativa fala sobre o exercício coletivo e cooperativo, ao passo em que a narração se estabelece num único ritmo em que compartilham e se complementam as memórias de Dona Brasília e Manoel de Delfina, há um intercâmbio dotado de sacralidade na representação da cena. O diálogo concebe-se em dança que entrelaça e exercita a memória de existências e humanidades que se realizam reciprocamente. O trabalho coletivo em prol do benefício de 
todos em função do atendimento à precisão dos con-viventes remete à afroperspectiva Ubuntu, que

pode ser traduzido como "o que é comum a todas as pessoas". A máxima zulue xhosa, umuntu ngumuntu ngabantu (uma pessoa é uma pessoa através de outras pessoas) indica que um ser humano só se realiza quando humaniza outros seres humanos. A desumanização de outros seres humanos é um impedimento para o autoconhecimento e a capacidade de desfrutar de todas as nossas potencialidades humanas. O que significa que uma pessoa precisa estar inserida numa comunidade, trabalhando em prol de si e de outras pessoas. (NOGUERA, 2012, p. 148).

Esta posição ratifica uma perspectiva de vida não afetada pelo racismo e/ou outras formas de hierarquização social. Os quilombolas de Volta Miúda são narradores, pois, além de recordar, têm a capacidade de transportar, com riqueza de detalhes e sonorizações, a si e a seus ouvintes à participação no fato contado, "de modo que seus ouvintes, assim como ele próprio, tomem-se testemunhas vivas e ativas desse fato" (HAMPATÉ BÂ, 2010, p. 210-211). As narrativas gravam cenas e contextos, e perpetuam sentimentos, incitam a reflexão, em prece, tecem a descolonização dos saberes.

Conversando com voz macia e firme, Manoel de Delfina ensina sobre as suas ancestralidades: "Minha bisavó era dos escravo; minha mãe nasceu da minha avó Joaquina no dia em que libertaram os escravo. Eu não sou do tempo dos escravo, mas ainda alembro do canto e das reza" (9 de fevereiro de 2019). O quilombola revela as histórias com performances que incluem palmas, cantos e danças, expressões de 
uma musicalidade que the é inerente, que aduz à vivacidade das suas origens. Santana (2014, p. 21), explica que:

Os cantos-poemas acionam reminiscências, evocam lembranças, cooperando para desconstruir as engrenagens e estruturas do engenho, as quais persistem na memória coletiva e revelam o chicotear que dilacerou corpos e mentes que não se submeteram aos mecanismos de poder e aos construtos de escravidão; as palavras cantadas trazem, entre o dito e o não dito, marcas de resistência, de poder e de magia, uma itinerância de morte e vida severa, contudo, libertária.

Dança e canto são rememorados e reconfigurados como espaços de resistência. Manoel de Delfina, durante incursão às ruínas da senzala, apontando para um terreiro com base em pedra, conta: "Treze de maio tinha bate barriga, que era festa de antigamente. É alegria porque terminou os escravo. 13 de maio. Ó, só vendo... 13 de maio, dia que a minha avó, mãe da minha mãe nasceu" (Manoel de Delfina, 3 de março de 2019). Brasília Firmina explica que a dança bate-barriga era "pra festejar [a liberdade] (...) Pr'a um bate barriga falava tambô. "Vai tê samba de tambô!'" (24 de junho de 2018). Nesse contexto,

a dança bate-barriga assume uma duplicidade de significação, ela é uma dança - expressão de movimento, bailado, samba e sentimento corpóreo-sensorial - como também é o lugar, o local onde reside um volume de estilhaços 
de memória. Um refúgio em que as lembranças se agregam à espera da composição da dança para se manifestarem, se recomporem; a dança e os dançantes como locais de resíduos possíveis de serem restaurados como performances. (DOS SANTOS, 2007, p. 84-85).

Noutros espaços de memória, a musicalidade também reflete embates de luta e conquista, sobre continuidade e vida implicada com a coletividade. Brasília Firmina conta sobre uma experiência íntima que, ao falar sobre uma ex-escravizada, conecta não apenas ela, mas a comunidade de Volta Miúda à sua herança africana:

\begin{abstract}
Minha bisavó quando trovejava ela tinha toalha, tinha roupa de conversá no tempo. Trovoada podia tá falando mesmo, ela marrava esse pano na cabeça, uma toalha branca, botava uma bacia com uma pedra dentro... uma bacia dessa bacia piquena e saía no tempo. Conversava, conversava, falava num sei o quê, não sei o quê lá, língua deles que ninguém sabe, falava, falava, daí a poco a trovoada tá trovejando lá longe. Não trovejava mais não. (3 de março de 2018).
\end{abstract}

Brasília (3 de março de 2018) fala também sobre a Mãe d'Água, e sobre a cantoria feita à beira da lagoa encantada para salvar uma moça que sumira no olho d'água, esta rememoração compreende o:

processo de reconhecimento, uma luta em busca das raízes e razões de ser quilombo, as mulheres, com seus cantos da Mãe d'Água, agricultoras e mãos hábeis de bordadeiras, almejam, de forma rizomática, diversa 
singularidade constituída no tempo e que delineia, de forma diferente, o ser e o agir, por meio de manifestações sócio-culturais e religiosas que parecem apontar para uma resistência e a manutenção de uma identidade construída ao longo dos enfrentamentos identitários ou dos jogos de poder, expressos em suas cantorias. (SANTANA, 2014, p. 71).

A escuta e escrita dessas memórias visam propiciar a que outras pessoas possam conhecer a Comunidade Quilombola de Volta Miúda e ser incentivadas à retomada da sua história e da primorosa habilidade como narradoras e narradores, (re)humanizando-se no presente, ampliando as possibilidades de interpretação sobre a sua própria existência e a dos quilombolas que resistem. Sob o lume das memórias, tecem-se alternativas decoloniais, cujas experiências e sensibilidade e fé e força poetizam a luta a fim de que outras trajetórias individuais e coletivas iluminem-se por uma história rica, múltipla, hábil a identificar a negritude e afrodescendência como símbolos de força e resistência.

O professor e doutor em filosofia Renato Noguera (2012, p. 147) chama de afroperspectiva "o conjunto de pontos de vista, estratégias, sistemas e modos de pensar e viver de matrizes africanas". Este é um convite para imersão no pluriverso de sentidos evocados pela vivência com as/os quilombolas de Volta Miúda... imersão que visa proporcionar a descolonização de perspectivas, práticas... para conduzir à revisitação das trajetórias individuais e do contexto sócio-histórico-político que o sistema colonial- capitalista impõe. Sigamos avante - ninguém solta a mão de ninguém. 
Manoel Reis, ao contar sobre a forma como se tornou rezador do Santo Ofício, enfatiza que aprendeu por observar, aprendeu a partir da experiência, ouvindo. Nas tradições africanas, a tradição oral é lida como conhecimento total, passado pelos mais velhos ao mais novos, àqueles que tenham ouvidos sensíveis - livres de pré-conceitos para aprender conhecimentos preservados há muitas gerações. Anciãs e anciãos são reconhecidos por toda a sabedoria e experiência acumulada durante a vida, e isso os dignifica.

Brasília Firmina fala sobre uma experiência íntima que, ao contar sobre uma ex-escrava, conecta não apenas ela, mas a comunidade remanescente de Volta Miúda à sua origem africana e à resistência que, com luta, conquistou a liberdade e a vem ressignificando ao encontrar espaços que ecoem sua voz.

Este livro, ao incentivar a retomada da sua história àqueles sujeitos e da sua primorosa habilidade como narradoras e narradores, (re)humaniza-os no presente, amplia aos leitores as possibilidades de interpretação sobre a sua própria existência, ensina aos mais jovens sobre uma história rica, múltipla, hábil a definir a cor da sua pele como símbolo de força e resistência. Sob o lume das memórias fala sobre vivências decoloniais, cujas experiências e sensibilidade e fé e força poetizam a luta e tecem resistência. 